\title{
Radical antegrade modular pancreatosplenectomy versus standard procedure in the treatment of left-sided pancreatic cancer: A systemic review and meta-analysis
}

Feng $\mathrm{CaO}^{\dagger}$, Jia $\mathrm{Li}^{\dagger}$, Ang Li and Fei $\mathrm{Li}^{*}$

\begin{abstract}
Background: Radical antegrade modular pancreatosplenectomy (RAMPS), first reported by Strasberg in 2003, has attracted increasing attention in the treatment of left-sided pancreatic cancer. The limited number of cases eligible for RAMPS makes it difficult to perform any prospective randomized trial of RAMPS versus the standard procedure. Therefore, we performed this systemic review and meta-analysis of the current data to clarify the role of the RAMPS procedure.

Methods: A literature search was performed in electronic databases, including PubMed, Medline, Embase, CNKI and the Cochrane Library. Studies comparing RAMPS with the standard procedure were included in this meta-analysis. RO resection rate, recurrence rate at the end of the follow-up, overall survival (OS) and disease-free survival (DFS) were measured as primary outcomes. Revman 5.3 was used to perform the analysis.

Results: Six retrospective cohort studies with a total number of 378 patients were included in our analysis. Meta-analysis revealed that RAMPS was correlated with higher R0 resection rates [Odds Ratio (OR) 95\% confidence interval $(\mathrm{Cl}), 2.19(1.16 \sim 4.13) ; P=0.02$ ] and successful harvest of more lymph nodes [weighted mean difference (WMD) 95\% Cl, 7.06 (4.52 9.60); $P<0.01$ compared with the standard procedure. However, no statistically significant difference was found between the procedures with respect to recurrence rates [OR $95 \% \mathrm{Cl}, 0.66(0.40 \sim 1.09) ; P=0.10$ ], OS [Hazard ratio (HR) $95 \% \mathrm{Cl}, 0.65(0.42 \sim 1.00) ; P=0.05]$ or DFS [HR 95\% Cl, $1.02(0.62 \sim 1.68) ; P=0.93]$.

Conclusions: RAMPS is safe and oncologically superior to the standard procedure for the treatment of left-sided pancreatic cancer. However, high-grade evidence will be necessary to confirm the potential survival benefits of RAMPS.
\end{abstract}

Keywords: Pancreatic body/tail cancer, Surgery, R0, Overall survival, Disease-free survival

\section{Background}

Distal pancreatectomy is the standard surgical approach for left-sided pancreatic cancer. However, the long-term survival of these patients remains unsatisfactory, with a median survival time of 10-28 months and a 5-year overall survival of $6-30 \%$ [1-5]. In recent years, new surgical approaches for resectable or borderline resectable

\footnotetext{
* Correspondence: feili36@ccmu.edu.cn

${ }^{\dagger}$ Equal contributors

Department of General Surgery, Xuanwu Hospital, Capital Medical University, Beijing 100053, People's Republic of China
}

pancreatic cancer, including the artery-first approach [6-9], superior mesenteric vein/portal vein resection and reconstruction [10-13], intraoperative radiotherapy $[14,15]$ and preoperative chemo-radiotherapy [16-18], have been increasingly applied to pancreaticoduodenectomy to achieve R0 resection for carcinomas of the head of the pancreas. Despite the highly aggressive nature of the disease and early regional lymph node metastasis, adenocarcinomas of the body and tail of the pancreas have attracted significantly less clinical attention. However, in 2003, Strasberg described a new distal pancreatectomy 
technique, termed radical antegrade modular pancreatosplenectomy (RAMPS), to achieve negative posterior resection margins and to completely remove the N1 lymph nodes [19]. In the past decade, the RAMPS procedure has been increasingly applied, particularly in Japan and Korea [20-24]. However, the number of patients eligible for RAMPS is too small to consider any prospective randomized trial of RAMPS versus the standard procedure. Therefore, systemic review and meta-analysis of the current retrospective data comparing RAMPS and the standard procedure are necessary and useful to clarify the role the RAMPS in the treatment of left-sided pancreatic cancer.

\section{Methods}

\section{Search strategy and selection of trials}

A computerized search was performed in July 2016 using the following terms: "radical antegrade modular pancreatosplenectomy" or "RAMPS". The following electronic databases were included: PubMed, Medline, Embase, CNKI and the Cochrane Library. The reference list of selected articles was also reviewed.

Randomized controlled trials (RCTs) and retrospective cohort studies (RCSs) comparing RAMPS and the standard procedure for the treatment of left-sided pancreatic cancer were included in this systemic review and meta-analysis. There were no limitations with respect to language or date. Case reports, review articles and letters were not included, and studies without any major postoperative outcomes were excluded from the search results.

\section{Data extraction and quality assessment}

Two reviewers (FC and JL) independently considered the eligibility of potential titles and extracted the data. Discrepancies were resolved by mutual discussion. Inclusion and exclusion criteria, country and year of publication, study type, number of patients operated on with each technique and the general characteristics of patients (age, gender, perioperative outcome and postoperative results) were extracted. The risk of bias for the trials enrolled in the meta-analysis was evaluated according to the Cochrane Handbook for Systematic Reviews of Interventions, and the quality of the non-randomized studies was assessed using the criteria suggested by the Newcastle-Ottawa quality assessment (NOS) tool [25]. This scale rates studies on a scale of one to nine, with nine representing the highest methodological quality, a NOS score of 7 or above considered high quality, and a NOS score of 3 or below considered low quality.

\section{Outcome measurements}

The primary outcomes of this study were R0 resection rate, overall survival (OS) and disease-free survival (DFS); secondary outcomes included recurrence rate at the end of the follow-up, postoperative complication rate, intraoperative blood loss, operative time, the number of lymph nodes harvested, combined resection rate and duration of hospital stay.

\section{Statistical analysis}

Meta-analysis was performed according to recommendations from the Cochrane Collaboration. Hazard ratios (HRs) and 95\% confidence intervals (CIs), derived from values reported explicitly in the published studies or calculated from the Kaplan-Meier survival curve using the methods reported by Tierney and colleagues [26], were combined to measure the survival rates. Odds ratios (ORs) and weighted mean differences (WMDs) were used to measure dichotomous and continuous data, respectively. A combined HR/OR $>1$ and WMD $>0$ indicated poor outcomes for patients in the RAMPS group (except R0 resection and the number of lymph node harvested). Heterogeneity was evaluated using the Chi-square test, and a $P$ value less than 0.1 was considered statistically significant. The fixed effect model was used throughout the analysis unless significant heterogeneity was detected. Funnel plot and Egger's test were used to investigate the publication bias. Analysis was performed using the Review Manager version 5.3 (Cochrane Collaboration, Software Update, Oxford, UK) and STATA/SE software version 12.0 (STATA Corporation, College Station, TX, USA).

\section{Results}

\section{Characteristics of the trials}

Six retrospective trials that met the inclusion criteria were included in the meta-analysis for a total of 378 patients, including 152 patients undergoing RAMPS and 226 patients undergoing the standard procedure [20, 24, 27-30]. Figure 1 summarized the study flow. The patient characteristics and surgical outcomes of the included trials are summarized in Tables 1 and 2 . No RCTs had been published at the time of our search. The risk of bias was evaluated by the Newcastle-Ottawa scale. Three studies earned a score of 7 or more and were considered high quality [20, 24, 30] (Additional file 1: Table S1). Outcomes may have been influenced by allocation bias in all studies for patients who underwent RAMPS or the standard procedure. Furthermore, the follow-up method was unclear in all of the studies.

\section{Meta-analysis results \\ Primary outcome}

R0 resection rate All of the included studies reported $\mathrm{R} 0$ resection rates [20, 24, 27-30]. The R0 resection rate was $89.5 \%(136 / 152)$ in the RAMPS group and $83.6 \%$ $(189 / 226)$ in the standard surgery group. The overall 


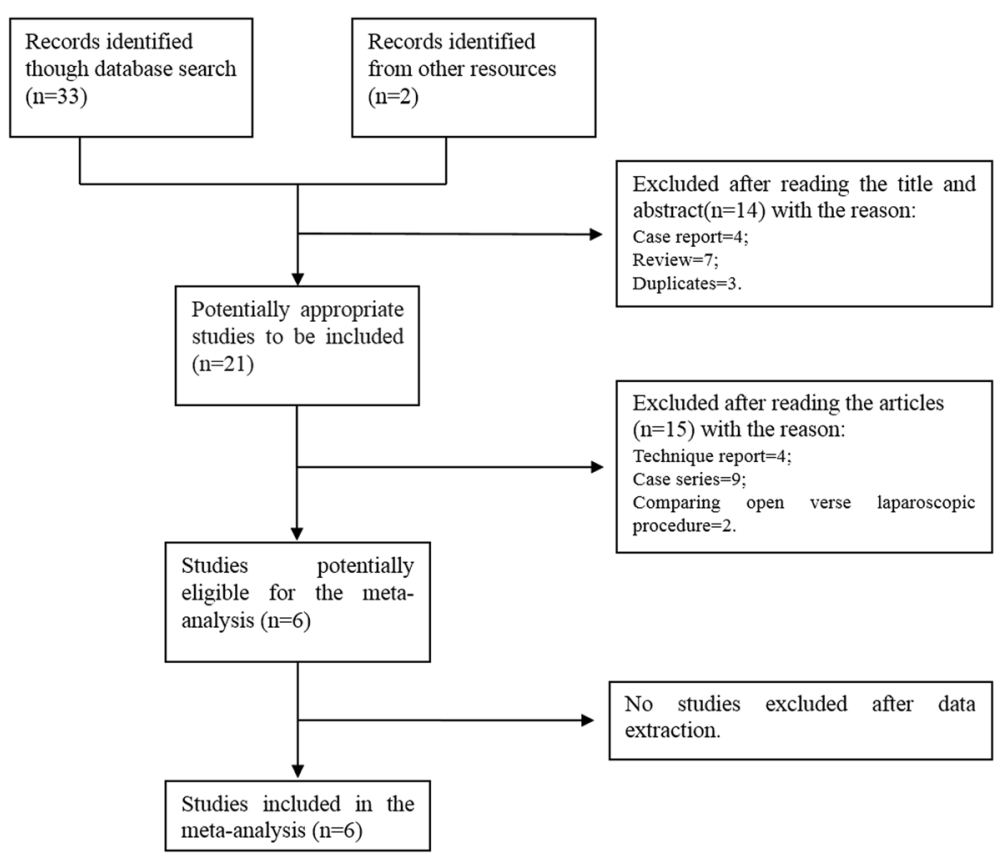

Fig. 1 Flow diagram of studies included in the meta-analysis

analysis revealed that the R0 resection rate was significantly higher in the RAMPS group than in the standard surgery group [OR 95\% CI, 2.19 (1.16 4.13); $P=0.02$ ] (Fig. 2a). Heterogeneity was not detected $(P=0.57$, $\mathrm{I}^{2}=0 \%$ ), and the fixed-effects model was used.

Recurrence rate at the end of the follow-up The four large studies reported recurrence rates at the end of the follow-up [20, 24, 29, 30]: $52.6 \%$ and $58.1 \%$ in the RAMPS and standard groups, respectively. Overall analysis revealed that there was no statistically significant difference between the groups with respect to the recurrence rate $[\mathrm{OR} 95 \% \mathrm{CI}, 0.66(0.40 \sim 1.09)$; $P=0.10]$ (Fig. 2b).

Overall survival Four of the included studies reported the overall survival rate $[20,24,28,30]$. Heterogeneity was not detected among these studies $(P=0.56$, $\left.\mathrm{I}^{2}=0 \%\right)$, and the fixed-effected model was used. Overall analysis revealed no significant difference between the RAMPS and standard surgery groups [HR 95\% CI, 0.65 (0.42 1.00); $P=0.05$ ] (Fig. 2c).

Disease-free survival Three studies reported diseasefree survival rates $[20,28,30]$. No significant difference was found when comparing RAMPS with the standard procedure [HR 95\% CI, $1.02(0.62 \sim 1.68) ; P=0.93$ ] using a fixed-effect model $\left(P=0.87, \mathrm{I}^{2}=0 \%\right)$ (Fig. $2 \mathrm{~d}$ ).

\section{Secondary outcomes}

Meta-analysis results for secondary outcomes, including postoperative complication rate, intraoperative blood loss, operative time, number of lymph nodes harvested, combined resection rate and duration of hospital stay, are summarized in Table 3. The number of lymph nodes harvested in the RAMPS group was significantly greater than that in the standard operation group [WMD 95\% CI, 7.06 (4.52 9.60); $P<0.01]$ without increased intraoperative blood loss [-85.11 (-278.08 107.85); $P=0.39]$. Despite the tendency toward higher combined resection rates [OR 95\% CI, 3.30 (1.00 10.93); $P=0.05$ ], the incidence of complications in the RAMPS group did not increase [OR 95\% CI, 0.94 (0.56 1.59); $P=0.83$ ]. There were no statistically significant differences between the groups with respect to operative time or duration of hospital stay (Additional file 2: Figure S1, Additional file 3: Figure S2, Additional file 4: Figure S3, Additional file 5: Figure S4, Additional file 6: Figure S5, Additional file 7: Figure S6).

\section{Sensitivity analyses}

To test the stability of the overall meta-analysis results, sensitivity analyses were conducted by excluding low quality studies [27-29]. The results of these analyses revealed no significant differences when compared with the former estimates (Additional file 8: Table S2).

\section{Publication bias}

Funnel plots for primary results were drawn to assess potential publication bias (Additional file 9: Figure S7). All of 


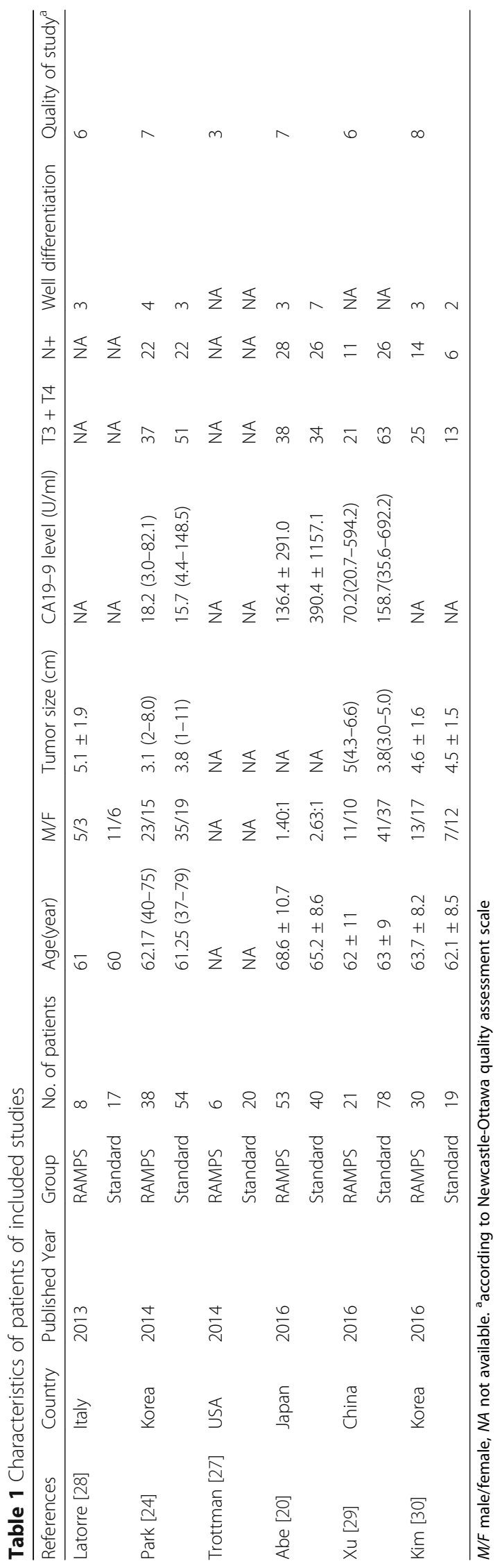




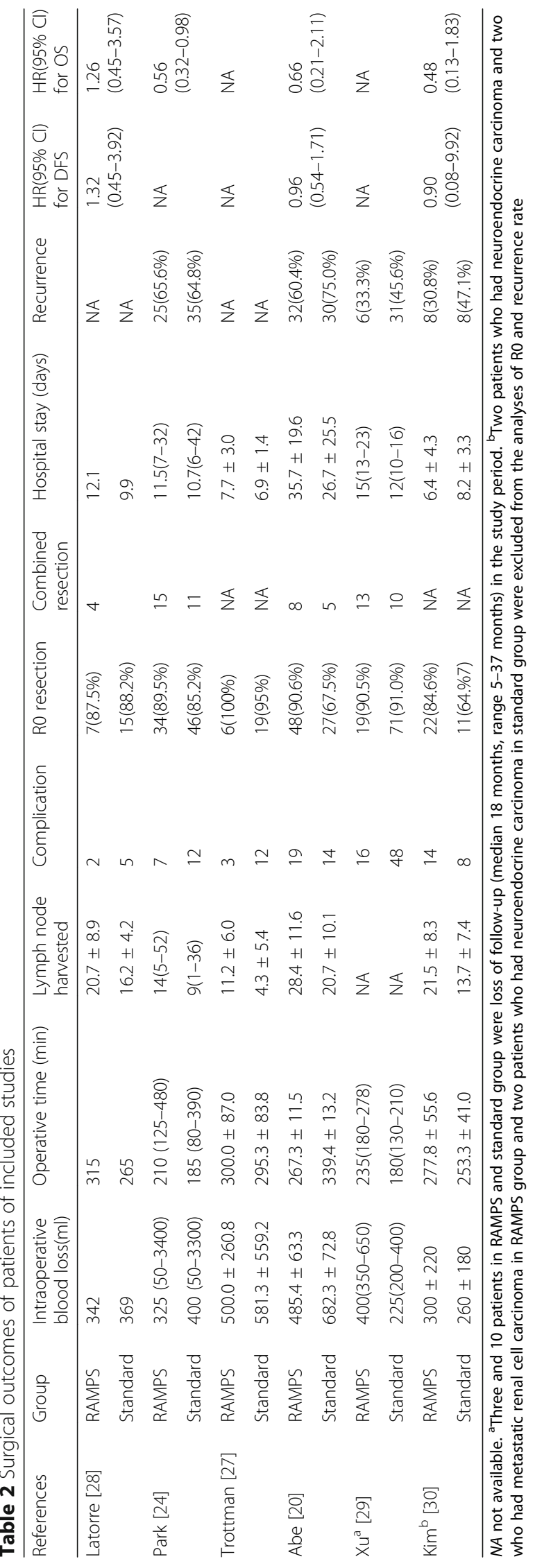




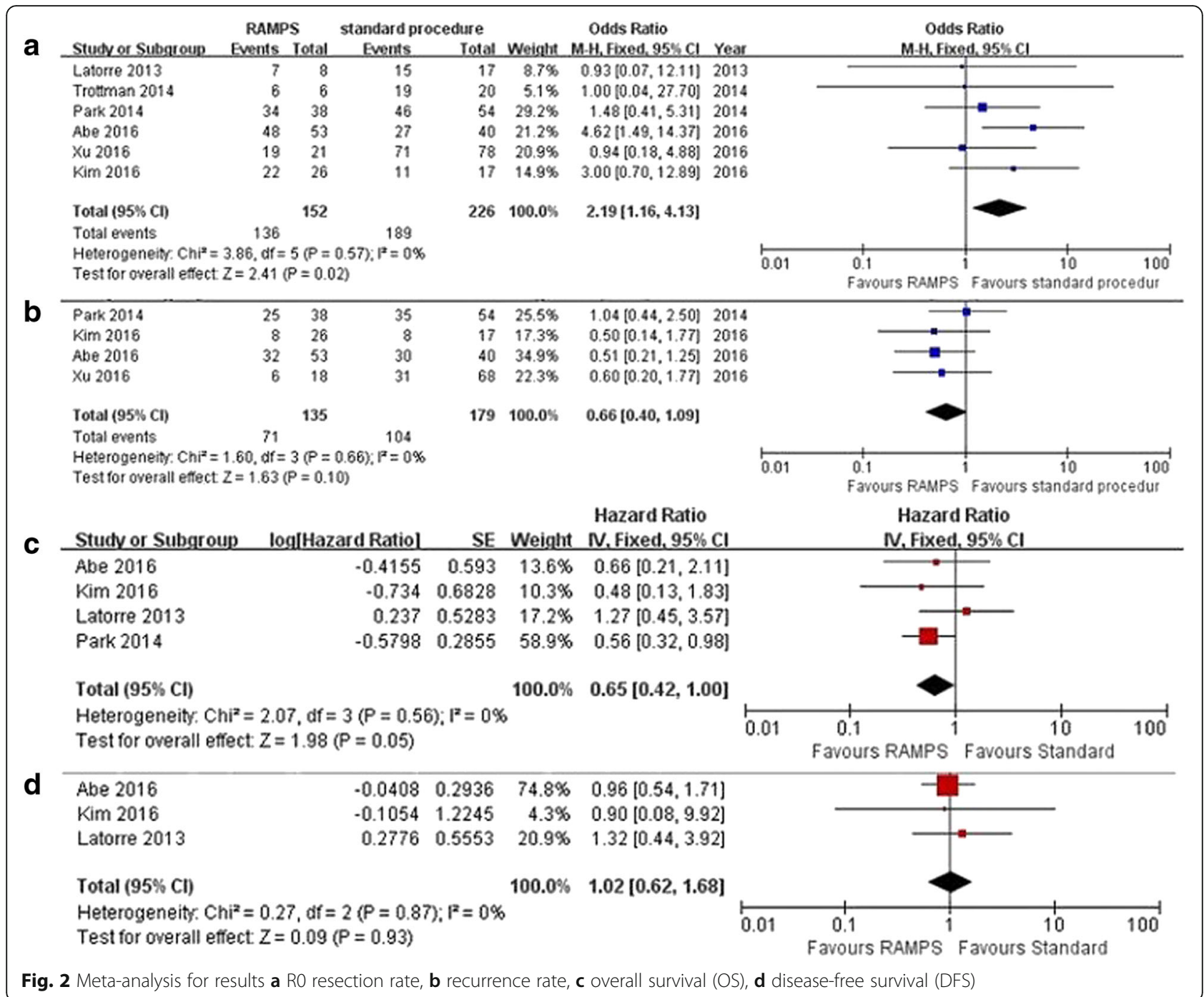

the plots were symmetrical, suggesting no reporting bias among the studies. Egger's test for OS $(t=0.51, P=0.659)$ and DFS $(t=0.33, P=0.795)$ revealed no publication bias.

\section{Discussion}

The RAMPS procedure, first reported in 2003, was designed to establish an operation with oncologic safety both with respect to the dissection planes used to achieve negative margins as well as the extent of lymph node dissection, thereby improving patient outcomes. According to the original paper by Strasberg, if the tumour did not penetrate the posterior capsule of the pancreas on preoperative CT scans, the resection plane lay just behind the anterior renal fascia, and anterior RAMPS was performed; otherwise,

Table 3 Secondly results of meta-analysis for RAMPS verse standard procedure in treatment of left-sided pancreatic cancer

\begin{tabular}{|c|c|c|c|c|c|c|c|}
\hline Outcome & Ref. included & $\begin{array}{l}\text { No. of patients with } \\
\text { RAMPS vs no standard }\end{array}$ & $\begin{array}{l}\text { Heterogeneity } \\
\text { Chi-square test }\end{array}$ & Model used & $\begin{array}{l}\text { OR or Mean } \\
\text { difference }\end{array}$ & $95 \% \mathrm{Cl}$ & $P$ value \\
\hline Intraoperative blood loss(ml) & {$[20,27,30]$} & 89 vs 79 & $P<0.01 ;\left.\right|^{2}=88 \%$ & Random effect & -85.11 & $-278.08-107.85$ & 0.39 \\
\hline Operating time (min) & {$[20,27,30]$} & 89 vs 79 & $P<0.01 ;\left.\right|^{2}=96 \%$ & Random effect & -16.81 & $-95.19-61.57$ & 0.67 \\
\hline Lymph node harvested & {$[20,27,28]$} & 93 vs 94 & $P=0.86 ; I^{2}=0 \%$ & Fixed effect & 7.06 & $4.52-9.60$ & $<0.01$ \\
\hline Complication & {$[20,24,27-29]$} & 135 vs 150 & $P=0.97 ;\left.\right|^{2}=0 \%$ & Fixed effect & 0.94 & $0.56-1.59$ & 0.83 \\
\hline Combined resection & {$[20,24,29]$} & 112 vs 172 & $P=0.02 ; I^{2}=73 \%$ & Random effect & 3.30 & $1.00-10.93$ & 0.05 \\
\hline Hospital stay (days) & {$[20,27,30]$} & 89 vs 79 & $P=0.04 ; I^{2}=68 \%$ & Random effect & 0.49 & $-2.97-3.94$ & 0.78 \\
\hline
\end{tabular}


posterior RAMPS was applied, and the left adrenal gland and Gerota fascia were removed [19]. Deep resection is performed because tumours can spread microscopically beyond their radiographically visible or palpable margins. The systemic review of descriptive studies concerning the RAMPS procedure for the treatment of left-sided pancreatic cancer is summarized in Table 4 . R0 resection was achieved in $77-100 \%$ of patients after RAMPS, and an R0 rate $>85 \%$ was observed in most case series. In this meta-analysis, we found that the R0 resection rate was significantly higher in the RAMPS group than in the standard surgery group [ $89.5 \%$ vs $83.6 \%$, OR $95 \% \mathrm{CI}$, 2.19 (1.16 4.13); $P=0.02$. However, the combined resection rates were comparable between the RAMPS and standard groups [OR 95\% CI, $3.30(1.00 \sim 10.93) ; P=0.05$ ], which might be attributable to the low rate of posterior RAMPS procedures in present practices [24, 31, 32].

Lymph node metastasis has been reported to be an independent prognostic risk factor for resected leftsided pancreatic cancer [33, 34]. The extent of lymph node dissection is one of the key points of pancreatosplenectomy. However, guidelines from Eastern and Western countries differ significantly. In the RAMPS procedure, the lymph nodes along the superior and inferior borders of the left-sided pancreas (No. 10, 11, and 18 according to Japanese classification), the celiac lymph nodes (No. 9) and the nodes along the front and left side of the superior mesenteric artery (No. 14p, 14d) are considered N1 lymph nodes and are completely removed; in the standard operation, only lymph nodes No. 10, 11, and 18 are resected [35]. Therefore, in this meta-analysis, we found that the number of lymph nodes harvested in the RAMPS procedure was significantly greater than in the standard operation [WMD 95\% CI, 7.06 (4.52-9.60); $P<0.01$ ]. Compared with the standard operation, the RAMPS procedure is reported to require greater technical skill for extensive resection as well as longer operating times [24, 28]. However, these differences were not detected in our metaanalysis [WMD 95\% CI, -16.81 (-95.19-61.57); $P=0.67$ ]. Additionally, RAMPS procedures were not correlated with longer hospital stays [WMD 95\% CI, 0.49 (-2.97-3.94); $P=0.78]$. These findings may be influenced by a recent study with a large volume of patients and more experienced surgeons.

Improving the survival of patients with resectable or borderline resectable tumours is the major aim of the RAMPS procedure. The 5-year survival rate after RAMPS ranged from $25.1 \%$ to $55.6 \%$ (Table 4 ). In a recent study, when comparing RAMPS and the standard procedure, RAMPS exhibited a greater tendency towards improvement of median survival times relative to the standard procedure (47 vs 34 months, $P=0.192$ ), but no significant differences in the recurrence rates were detected (66.6 vs $75.0 \%$;
$P=0.1386)[20]$. In the study by Park, the 5-year overall survival rate was $40.1 \%$ in RAMPS patients and $12.0 \%$ in the standard group $(p=0.014)$. However, by multivariate analysis, adjuvant chemoradiotherapy but not RAMPS reached statistical significance with respect to overall survival [24]. In the present study, no favourable overall survival outcomes were detected when comparing RAMPS with the standard procedure. The recurrence rate after RAMPS did not decrease $(65.7 \%$ vs $64.8 \%, P=0.482)$, which was consistent with our meta-analysis [OR 95\% CI, 0.66 (0.40 1.09); $P=0.10$ ] and led to similar DFS rates in the two groups [OR 95\% CI, $1.02(0.62 \sim 1.68) ; P=0.93$ ]. With respect to recurrence, we believed that it is important to differentiate local recurrence from systemic recurrence. RAMPS increased the R0 resection rate and theoretically may decrease local recurrence. Unfortunately, few studies reported the local recurrence rate. In these studies, systemic recurrence alone, such as liver, lung and peritoneum, was reported most often, and the local recurrence rate did not decrease significantly after RAMPS [20, 31].

Recently, a modified RAMPS procedure including a superior mesenteric artery (SMA)-first approach has been attempted [22, 36-38]. The artery-first approach, initially designed for the early determination of cancer resectability during pancreatoduodenectomy, is now applied in the RAMPS procedure. As described by Strasberg, dissection of the SMA is performed after transection of the pancreas or wide detachment of the distal pancreas and spleen, which may reach the point of no return. However, carcinoma of the pancreatic body and tail exhibits high aggressive potential, and the celiac axis (CA) and SMA are often involved. Although left-sided pancreatic cancer with CA invasion can be treated by distal pancreatectomy combined with celiac axis resection (DP-CAR), SMA encroachment usually indicates that the tumour is a late-stage lesion and may be completely unresectable. SMA-first RAMPS provides an opportunity to determine resectability before pancreas transection. Dissection further along the aorta and exposure of the left renal vein and the left adrenal gland can help prepare the correct RAMPS dissection plane in advance. When the renal vein is reached, the surgeon can accurately assess the extent of tumour penetration to help decide whether anterior or posterior RAMPS is optimal. Data from Japan has demonstrated the safety and reliability of this procedure even in borderline resectable tumours [22, 36, 37].

Laparoscopic or robotic RAMPS operations have also been performed with satisfactory oncological results and survival outcomes [39-41]. However, this procedure is limited to highly selective cases. According to the Yonsei criteria developed by Lee, only patients meeting the following characteristics can be treated with minimally invasive RAMPS: (1) tumour confined to the pancreas, (2) intact fascial layer between the distal pancreas and 


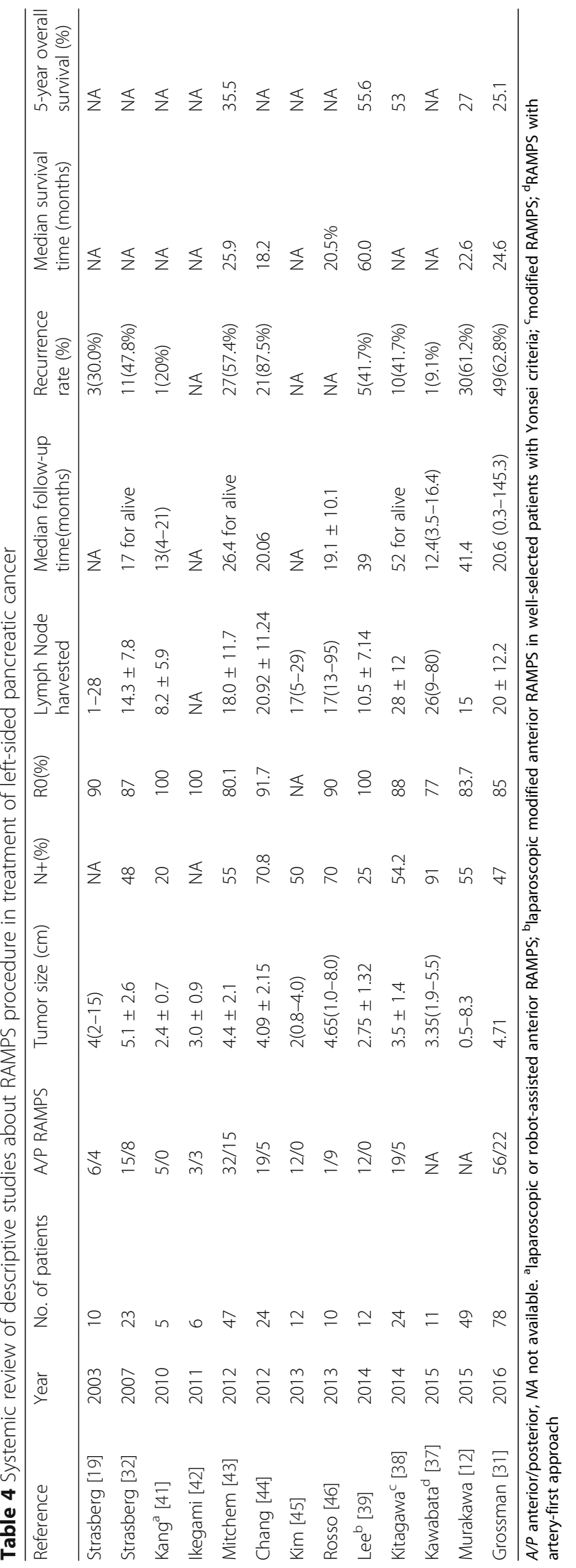


the left adrenal gland and kidney, and (3) tumour located more than 1-2 cm from the celiac axis [39].

An important limitation of this review is the small number of included studies and cases. In addition, the nature of the included retrospective studies may lead to allocation and publication biases and could distort the conclusions of this review. However, this study represents the initial attempt to perform a systemic review and metaanalysis of RAMPS versus the standard procedure in the treatment of left-sided pancreatic cancer. Our systematic review and meta-analysis presents evidence to suggest that RAMPS is the optimal procedure to increase R0 resection rates but has no increased benefit with respect to tumour recurrence or patient survival.

\section{Conclusion}

The RAMPS procedure for the treatment of left-sided pancreatic cancer can achieve higher rates of R0 resection without increasing complication rates compared with the standard procedure. However, high-grade evidence is required before any conclusions may be made concerning the survival benefit of RAMPS.

\section{Additional files}

Additional file 1: Table S1. Risk of bias in the included retrospective cohort studies (by the Newcastle-Ottawa quality assessment tool). (DOCX $12 \mathrm{~kb}$ )

Additional file 2: Figure S1. Meta-analysis for lymph node harvested showed significantly greater in RAMPS group. (PNG 9 kb)

Additional file 3: Figure S2. Meta-analysis revealed compared result for intraoperative blood loss. (PNG $10 \mathrm{~kb}$ )

Additional file 4: Figure S3. Meta-analysis for combined resection rate. RAMPS procedure did not combined resection rate. (PNG 9 kb)

Additional file 5: Figure S4. Meta-analysis revealed that RAMPS did not increase the complication. (PNG $10 \mathrm{~kb}$ )

Additional file 6: Figure S5. Meta-analysis for operation time showed compared result between RAMPS and standard procedure. (PNG $10 \mathrm{~kb}$ )

Additional file 7: Figure S6. Meta-analysis revealed similar hospital stay in RAMPS and standard procedure. (PNG 9 kb)

Additional file 8: Table S2. Results of sensitivity analyses which revealed no significant differences when compared with main analyses. (DOCX $13 \mathrm{~kb}$ )

Additional file 9: Figure S7. Funnel plots for (a) R0 resection, (b) recurrence, (c) OS and (d) DFS revealed no publication bias. (PNG $182 \mathrm{~kb}$ )

\section{Acknowledgements}

None.

\section{Funding}

This work is partly supported by Beijing Municipal Administration of Hospitals' Youth Programme, code: QML20160806.

\section{Availability of data and materials}

All the data are available without restriction. Researchers can obtain data by contacting the corresponding author.

\section{Authors' contributions}

FC and FL designed this study. FC, AL and $J \mathrm{~L}$ collected and analyzed the data. FC wrote the first draft of the manuscript. All authors contributed to review the manuscript. All authors read and approved the final manuscript.

\section{Competing interests}

The authors declare that they have no competing interest.

Consent for publication

Not applicable.

Ethics approval and consent to participate

Not applicable.

\section{Publisher's Note}

Springer Nature remains neutral with regard to jurisdictional claims in published maps and institutional affiliations.

Received: 15 January 2017 Accepted: 15 May 2017

Published online: 05 June 2017

\section{References}

1. Wu X, Tao R, Lei R, Han B, Cheng D, Shen B, Peng C. Distal pancreatectomy combined with celiac axis resection in treatment of carcinoma of the body/ tail of the pancreas: a single-center experience. Ann Surg Oncol. 2010;17(5): 1359-66.

2. Yamamoto J, Saiura A, Koga R, Seki M, Katori M, Kato Y, Sakamoto Y, Kokudo $\mathrm{N}$, Yamaguchi T. Improved survival of left-sided pancreas cancer after surgery. Jpn J Clin Oncol. 2010;40(6):530-6.

3. Reddy SK, Tyler DS, Pappas TN, Clary BM. Extended resection for pancreatic adenocarcinoma. Oncologist. 2007;12(6):654-63.

4. van Gulik TM, Nakao A, Obertop H. Extended resection for pancreatic adenocarcinoma. HPB (Oxford). 2002;4(3):101-3.

5. Dalton RR, Sarr MG, van Heerden JA, Colby TV. Carcinoma of the body and tail of the pancreas: is curative resection justified? Surgery. 1992;111(5):489-94.

6. Pandanaboyana $S$, Bell $R$, Windsor J. Artery first approach to pancreatoduodenectomy: current status. ANZ J Surg. 2016;86(3):127-32.

7. Inoue Y, Saiura A, Yoshioka R, Ono Y, Takahashi M, Arita J, Takahashi Y, Koga R. Pancreatoduodenectomy with systematic Mesopancreas dissection using a Supracolic anterior artery-first approach. Ann Surg. 2015;262(6):1092-101.

8. Nagakawa Y, Hosokawa Y, Sahara Y, Takishita C, Nakajima T, Hijikata Y, Tago T, Kasuya K, Tsuchida A. A novel "artery first" approach allowing safe resection in laparoscopic Pancreaticoduodenectomy: the Uncinate process first approach. Hepato-Gastroenterology. 2015;62(140):1037-40.

9. Pittau G, Sanchez-Cabus S, Laurenzi A, Gelli M, Cunha AS. Laparoscopic Pancreaticoduodenectomy: right posterior superior mesenteric artery "first" approach. Ann Surg Oncol. 2015:22(Suppl 3):S345-8.

10. Xing-Mao Z, Hua F, Jian-Tao K, Xin-Xue Z, Ping L, Yang D, Qiang H. Resection of portal and/or superior mesenteric vein and reconstruction by using allogeneic vein for pT3 pancreatic cancer. J Gastroenterol Hepatol. 2016;31(8):1498-503.

11. Ramacciato G, Nigri G, Petrucciani N, Pinna AD, Ravaioli M, Jovine E, Minni F, Grazi GL, Chirletti P, Tisone G, et al. Pancreatectomy with mesenteric and portal vein resection for borderline Resectable pancreatic cancer: multicenter study of 406 patients. Ann Surg Oncol. 2016;23(6):2028-37.

12. Murakami Y, Satoi S, Motoi F, Sho M, Kawai M, Matsumoto I, Honda G. Portal or superior mesenteric vein resection in pancreatoduodenectomy for pancreatic head carcinoma. Br J Surg. 2015;102(7):837-46.

13. Wang WL, Ye S, Yan S, Shen Y, Zhang M, Wu J, Zheng SS. Pancreaticoduodenectomy with portal vein/superior mesenteric vein resection for patients with pancreatic cancer with venous invasion. Hepatobiliary Pancreat Dis Int. 2015;14(4):429-35

14. Jingu K, Tanabe T, Nemoto K, Ariga H, Umezawa R, Ogawa Y, Takeda K, Koto M, Sugawara T, Kubozono M, et al. Intraoperative radiotherapy for pancreatic cancer: 30-year experience in a single institution in Japan. Int J Radiat Oncol Biol Phys. 2012;83(4):e507-11.

15. Ogawa K, Karasawa K, Ito Y, Ogawa Y, Jingu K, Onishi H, Aoki S, Wada H, Kokubo $\mathrm{M}$, Etoh $\mathrm{H}$, et al. Intraoperative radiotherapy for resected pancreatic cancer: a multi-institutional retrospective analysis of 210 patients. Int J Radiat Oncol Biol Phys. 2010;77(3):734-42. 
16. Hirata T, Teshima T, Nishiyama K, Ogawa K, Otani K, Kawaguchi Y, Konishi K, Tomita Y, Takahashi H, Ohigashi H, et al. Histopathological effects of preoperative chemoradiotherapy for pancreatic cancer: an analysis for the impact of radiation and gemcitabine doses. Radiother Oncol. 2015;114(1):122-7.

17. Eguchi H, Nagano H, Tanemura M, Takeda Y, Marubashi S, Kobayashi S, Kawamoto K, Wada H, Hama N, Akita H, et al. Preoperative chemoradiotherapy, surgery and adjuvant therapy for resectable pancreatic cancer. Hepato-Gastroenterology. 2013;60(124):904-11.

18. Vento P, Mustonen H, Joensuu T, Karkkainen P, Kivilaakso E, Kiviluoto T. Impact of preoperative chemoradiotherapy on survival in patients with resectable pancreatic cancer. World J Gastroenterol. 2007;13(21):2945-51.

19. Strasberg SM, Drebin JA, Linehan D. Radical antegrade modular pancreatosplenectomy. Surgery. 2003;133(5):521-7.

20. Abe T, Ohuchida K, Miyasaka Y, Ohtsuka T, Oda Y, Nakamura M. Comparison of surgical outcomes between radical Antegrade modular Pancreatosplenectomy (RAMPS) and standard retrograde Pancreatosplenectomy (SPRS) for left-sided pancreatic cancer. World J Surg. 2016;40(9):2267-75.

21. Murakawa M, Aoyama T, Asari M, Katayama Y, Yamaoku K, Kanazawa A, Higuchi A, Shiozawa M, Kobayashi S, Ueno M, et al. The short- and long-term outcomes of radical antegrade modular pancreatosplenectomy for adenocarcinoma of the body and tail of the pancreas. BMC Surg. 2015;15:120.

22. Ome Y, Hashida K, Yokota M, Nagahisa Y, Michio O, Kawamoto K. Laparoscopic radical antegrade modular pancreatosplenectomy for leftsided pancreatic cancer using the ligament of Treitz approach. Surg Endosc. 2017. doi:10.1007/s00464-017-5561-6. [Epub ahead of print].

23. Han DH, Kang CM, Lee WJ, Chi HS. A five-year survivor without recurrence following robotic anterior radical antegrade modular pancreatosplenectomy for a well-selected left-sided pancreatic cancer. Yonsei Med J. 2014;55(1):276-9.

24. Park HJ, You DD, Choi DW, Heo JS, Choi SH. Role of radical antegrade modular pancreatosplenectomy for adenocarcinoma of the body and tail of the pancreas. World J Surg. 2014;38(1):186-93.

25. Stang A. Critical evaluation of the Newcastle-Ottawa scale for the assessment of the quality of nonrandomized studies in meta-analyses. Eur J Epidemiol. 2010;25(9):603-5.

26. Tierney JF, Stewart LA, Ghersi D, Burdett S, Sydes MR. Practical methods for incorporating summary time-to-event data into meta-analysis. Trials. 2007;8:16.

27. Trottman P, Swett K, Shen P, Sirintrapun J. Comparison of standard distal pancreatectomy and splenectomy with radical antegrade modular pancreatosplenectomy. Am Surg. 2014;80(3):295-300.

28. Latorre M, Ziparo V, Nigri G, Balducci G, Cavallini M, Ramacciato G. Standard retrograde pancreatosplenectomy versus radical antegrade modular pancreatosplenectomy for body and tail pancreatic adenocarcinoma. Am Surg. 2013;79(11):1154-8.

29. Xu D, Jiang KR, Lu ZP, Guo F, Chen JM, Wei JS, Yin J, Zhang K, Wu PF, Cai $B B, L v N$, Miao Y. Clinical effect of radical antegrade modular pancreatosplenectomy for carcinoma of pancreatic body and tail. Zhong Hua Xiao Hua Wai Ke Za Zhi. 2016;15(6):567-73.

30. Kim EY, You YK, Kim DG, Hong TH. Initial experience with radical antegrade modular pancreatosplenectomy in a single institution. Ann Surg Treat Res. 2016;91(1):29-36.

31. Grossman JG, Fields RC, Hawkins WG, Strasberg SM. Single institution results of radical antegrade modular pancreatosplenectomy for adenocarcinoma of the body and tail of pancreas in 78 patients. J Hepatobiliary Pancreat Sci. 2016;23(7):432-41.

32. Strasberg SM, Linehan DC, Hawkins WG. Radical antegrade modular pancreatosplenectomy procedure for adenocarcinoma of the body and tail of the pancreas: ability to obtain negative tangential margins. J Am Coll Surg. 2007;204(2):244-9.

33. Fujita T, Nakagohri T, Gotohda N, Takahashi S, Konishi M, Kojima M, Kinoshita T. Evaluation of the prognostic factors and significance of lymph node status in invasive ductal carcinoma of the body or tail of the pancreas. Pancreas. 2010;39(1):e48-54.

34. Shimada K, Sakamoto Y, Sano T, Kosuge T. Prognostic factors after distal pancreatectomy with extended lymphadenectomy for invasive pancreatic adenocarcinoma of the body and tail. Surgery. 2006;139(3):288-95.

35. Tol JA, Gouma DJ, Bassi C, Dervenis C, Montorsi M, Adham M, AndrenSandberg A, Asbun HJ, Bockhorn M, Buchler MW, et al. Definition of a standard lymphadenectomy in surgery for pancreatic ductal adenocarcinoma: a consensus statement by the international study group on pancreatic surgery (ISGPS). Surgery. 2014;156(3):591-600.
36. Aosasa S, Nishikawa M, Hoshikawa M, Noro T, Yamamoto J. Inframesocolic superior mesenteric artery first approach as an introductory procedure of radical Antegrade modular Pancreatosplenectomy for carcinoma of the pancreatic body and tail. J Gastrointest Surg. 2016;20(2):450-4.

37. Kawabata Y, Hayashi H, Takai K, Kidani A, Tajima Y. Superior mesenteric artery-first approach in radical antegrade modular pancreatosplenectomy for borderline resectable pancreatic cancer: a technique to obtain negative tangential margins. J Am Coll Surg. 2015;220(5):e49-54.

38. Kitagawa H, Tajima H, Nakagawara H, Makino I, Miyashita T, Terakawa H, Nakanuma S, Hayashi H, Takamura H, Ohta T. A modification of radical antegrade modular pancreatosplenectomy for adenocarcinoma of the left pancreas: significance of en bloc resection including the anterior renal fascia. World J Surg. 2014;38(9):2448-54.

39. Lee SH, Kang CM, Hwang HK, Choi SH, Lee WJ, Chi HS. Minimally invasive RAMPS in well-selected left-sided pancreatic cancer within Yonsei criteria: long-term (>median 3 years) oncologic outcomes. Surg Endosc. 2014;28(10): 2848-55.

40. Poves I, Burdio F, Membrilla E, Alonso S, Grande L. Laparoscopic radical antegrade modular pancreatosplenectomy. Cir Esp. 2010;88(1):51-3.

41. Kang CM, Kim DH, Lee WJ. Ten years of experience with resection of leftsided pancreatic ductal adenocarcinoma: evolution and initial experience to a laparoscopic approach. Surg Endosc. 2010;24(7):1533-41.

42. Ikegami T, Maeda T, Oki E, Kayashima H, Ohgaki K, Sakaguchi Y, Shirabe K, Maehara Y. Antegrade en bloc distal pancreatectomy with plexus hanging maneuver. J Gastrointest Surg. 2011;15(4):690-3.

43. Mitchem JB, Hamilton N, Gao F, Hawkins WG, Linehan DC, Strasberg SM Long-term results of resection of adenocarcinoma of the body and tail of the pancreas using radical antegrade modular pancreatosplenectomy procedure. J Am Coll Surg. 2012;214(1):46-52.

44. Chang YR, Han SS, Park SJ, Lee SD, Yoo TS, Kim YK, Kim TH, Woo SM, Lee WJ, Hong EK. Surgical outcome of pancreatic cancer using radical antegrade modular pancreatosplenectomy procedure. World J Gastroenterol. 2012;18(39): 5595-600.

45. Kim SH, Kang CM, Satoi S, Sho M, Nakamura Y, Lee WJ. Proposal for splenectomy-omitting radical distal pancreatectomy in well-selected leftsided pancreatic cancer: multicenter survey study. J Hepatobiliary Pancreat Sci. 2013;20(3):375-81.

46. Rosso E, Langella S, Addeo P, Nobili C, Oussoultzoglou E, Jaeck D, Bachellier P. A safe technique for radical antegrade modular pancreatosplenectomy with venous resection for pancreatic cancer. J Am Coll Surg. 2013;217(5):e35-9.

\section{Submit your next manuscript to BioMed Central and we will help you at every step:}

- We accept pre-submission inquiries

- Our selector tool helps you to find the most relevant journal

- We provide round the clock customer support

- Convenient online submission

- Thorough peer review

- Inclusion in PubMed and all major indexing services

- Maximum visibility for your research

Submit your manuscript at www.biomedcentral.com/submit
Biomed Central 